\title{
(6) OPEN ACCESS \\ Prevalence of alcohol related attendance at an inner city emergency department and its impact: a dual prospective and retrospective cohort study
}

\author{
Kathryn Parkinson, ${ }^{1}$ Dorothy Newbury-Birch, ${ }^{1}$ Angela Phillipson, ${ }^{2}$ Paul Hindmarch, ${ }^{2}$ \\ Eileen Kaner, ${ }^{1}$ Elaine Stamp, ${ }^{1}$ Luke Vale, ${ }^{1}$ John Wright, ${ }^{2}$ Jim Connolly ${ }^{2}$
}

\begin{abstract}
- Additional material is published online only. To view please visit the journal online (http://dx.doi.org/10.1136/ emermed-2014-204581)

${ }^{1}$ Institute of Health and Society, Newcastle University, Newcastle upon Tyne, UK ${ }^{2}$ Emergency Department, Royal Victoria Infirmary, Newcastle upon Tyne, UK
\end{abstract}

Correspondence to Dr K Parkinson, Institute of Health and Society, Newcastle University, Baddiley-Clark Building, Richardson Road, Newcastle upon Tyne NE2 4AX, UK;

kathryn.parkinson@ncl.ac.uk

Received 12 December 2014 Revised 1 September 2015 Accepted 7 October 2015

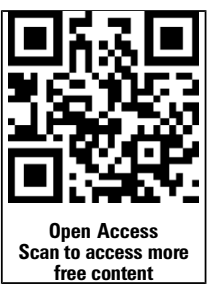

\section{CSLinked}

- http://dx.doi.org/10.1136/ emermed-2015-205295

\section{CrossMark}

\section{To cite: Parkinson $\mathrm{K}$,} Newbury-Birch D, Phillipson A, et al. Emerg Med J 2016;33:187-193.

\section{ABSTRACT}

Background Alcohol related hospital attendances are a potentially avoidable burden on emergency departments (EDs). Understanding the number and type of patients attending EDs with alcohol intoxication is important in estimating the workload and cost implications. We used best practice from previous studies to establish the prevalence of adult alcohol related ED attendances and estimate the costs of clinical management and subsequent health service use. Methods The setting was a large inner city ED in northeast England, UK. Data were collected via (i) retrospective review of hospital records for all ED attendances for four pre-specified weeks in 2010/2011 to identify alcohol related cases along with 12 months of follow-up of the care episode and (ii) prospective 24/7 assessment via breath alcohol concentration testing of patients presenting to the ED in the corresponding weeks in 2012/2013.

Results The prevalence rates of alcohol related attendances were $12 \%$ and $15 \%$ for the retrospective and prospective cohorts, respectively. Prospectively, the rates ranged widely from $4 \%$ to $60 \%$ across week days, rising to over $70 \%$ at weekends. Younger males attending in the early morning hours at weekends made up the largest proportion of alcohol related attendances. The mean cost per attendance was $£ 249$ (SD £1064); the mean total cost for those admitted was $\mathrm{f} 851$ (SD f2549). The most common reasons for attending were trauma related injuries followed by psychiatric problems.

Conclusions Alcohol related attendances are a major and avoidable burden on emergency care. However targeted interventions at weekends and early morning hours could capture the majority of cases and help prevent future re-attendance.

\section{INTRODUCTION}

Alcohol consumption is a major concern for public health. In 2010, alcohol use accounted for approximately 2.7 million deaths and 4\% of global disability adjusted life years. ${ }^{1}$ In economic terms, it is estimated that alcohol consumption accounts for between $1.3 \%$ and $3.3 \%$ of health costs globally, ${ }^{2}$ and that disease and injury attributable to alcohol use and alcohol use disorders account for more than $1 \%$ of the gross national product in high income and middle income countries. ${ }^{3}$ Such costs include attendances at emergency departments (EDs) that are directly or indirectly associated with alcohol related problems. The majority of these

\section{Key messages}

What is already known on this subject?

- Alcohol related attendances at emergency departments in the UK are a significant burden on the National Health Service.

- Many alcohol related attendances are readily preventable.

- The emergency department provides an opportunity for screening and intervention.

What might this study add?

- We provide prevalence and cost estimates of alcohol related attendances to emergency departments based on 24/7 coverage of 4 whole weeks, across each season of a year.

- We describe the profile of alcohol related attendees and the clinical reason for the presentation.

- We show a clear need for screening and alcohol intervention work to reduce potentially avoidable attendances in this challenging environment.

attendances at EDs are preventable and so most of the cost is avoidable. Thus these resources could be used to meet other clinical demands. In light of the increasing evidence supporting the effectiveness and cost effectiveness of screening and brief alcohol intervention in $\mathrm{EDs},{ }^{3-7}$ accurate data on the extent of alcohol related attendances is needed to inform intervention strategies. ${ }^{8}$

Previous studies have examined the relationship between alcohol and ED attendances. Retrospective studies of medical records suggest alcohol related ED attendance rates range from $1.2 \%$ in Belgium to $28 \%$ in the USA. $^{9-12}$ Self-reported data from rural Australia showed that $9 \%$ of ED visits were due to alcohol, ${ }^{13}$ and in young adults the prevalence was $40 \%{ }^{14}$ A prospective 4 week study (representing 1 week overall) reported that $14 \%$ of ED attendances were attributable to alcohol according to patients and $21 \%$ according to clinicians. ${ }^{15}$ A Colombian study based on clinical assessment reported a prevalence of $21.6 \%,{ }^{16}$ while in South Africa a third of trauma unit patients were positive for alcohol use, identified via self-report and breath alcohol concentration (BrAC) tests. ${ }^{17}$ Finally, a survey of weekend attendances using breath samples in a random sample of EDs in England 
reported that $40 \%$ of patients overall and up to $70 \%$ at peak times had recently consumed alcohol. ${ }^{18}$

These prior studies used various methodologies with a number of limitations. Some focused on injury or trauma patients rather than all ED patients. ${ }^{9} 1617$ The use of retrospective medical notes ${ }^{10-12}$ is subject to recording error and prospective studies which collect patient reported information $^{15}$ can be subject to response and recall bias. Other limitations were restrictions to particular age groups, ${ }^{14}$ or particular times of the day, ${ }^{12}$ week $^{18}$ or year. ${ }^{12-15} 18$ To our knowledge, no previous study has reported data on all alcohol related attendances across the entire week and across all seasons of the year.

This study combined the strengths of retrospective and prospective data collected across 4 whole weeks during a year to capture the effect of 'pay days', bank holidays and seasonal trends. The primary aim was to determine the prevalence of alcohol related ED attendances. The secondary aim was to establish the costs of clinical management and related health costs on emergency care.

\section{METHODS}

\section{Setting}

The ED of a large inner city hospital in northeast England.

\section{Measures and procedures}

Data for two cohorts of patients aged 18 years and over were gathered, each for pre-specified equivalent periods in 2010/ 2011 and 2012/2013 (table 1). Within the relevant calendar years, 1 week per quarter was selected to cover the first, second, third and fourth weeks of the month. Each week of data collection ran from 00:00 on day 1 to $24: 00$ on day 7 .

\section{Retrospective data (2010/2011)}

Computer based records (attendance database logs and erecords) and paper based hospital patient records (ED casualty cards and ambulance patient report forms) were screened for ED attendances involving alcohol. All records which included the terms 'alcohol', 'intoxication' or a type of alcohol consumed by the patient (eg, 'patient reported drinking cider') were categorised as alcohol related attendances in the dataset. An inventory of medical record numbers and attendance dates were used to ensure patients were not included in the dataset more than once. Each identified alcohol related case was matched on medical record number and National Health Service (NHS) number, and details of attendance at ED, hospital admissions, and any subsequent ED and hospital attendances within 12 months from first presentation were recorded.

\section{Prospective data (2012/2013)}

Breath samples were collected from patients to provide a noninvasive and objective measure of alcohol intake. Research nurses and other medical staff (referred to as 'researchers' in this article) collected BrAC measurements using a hand held breathalyser (Dräger Alcotest 6810 med). It was planned to have one researcher to cover each shift during weekdays with an additional researcher to cover Friday and Saturday nights. During the first week of data collection it was recognised that patients could be missed during staff breaks and staff handover times. For the remaining weeks, staff coverage was increased when possible so that in total 84 shifts $(56 \%)$ were covered by one researcher and 31 shifts (37\%) were covered by two researchers; 6 shifts $(7 \%)$ were not covered.

Following informed verbal consent, all consenting adult patients were asked to provide brief background information and their breath sample. In cases where the patient lacked the capacity to consent, either an accompanying adult capable of advising on the patient's likely willingness to consent to participation or an appointed consultee (clinician unrelated to the study) consented on the patient's behalf. The duty consultant advised in cases where patients could not be approached (eg, unconsciousness, serious illness, serious injury, risk of violence or excessive pain) as to whether alcohol had been ingested in the preceding $6 \mathrm{~h}$.

Caldicott approval was granted from the Newcastle upon Tyne Hospitals NHS Foundation Trust to gain access to the full hospital patient records. A favourable ethical opinion for the prospective data collection was obtained from NRES Committee North East-Newcastle and North Tyneside 2 REC Reference 12/NE/0063.

\section{Statistical analysis}

The costs of ED attendance and subsequent healthcare were extrapolated from the hospital patient notes (outpatient consultations, inpatient stays, tests and procedures) collected as part of the retrospective dataset. For each participant, using unit costs taken from NHS reference costs and from the Personal Social Care Research Unit, ${ }^{19}$ an attendance cost was applied and subsequent costs were added as appropriate (such as X-rays and admissions to wards).

Table 1 Description of datasets

\begin{tabular}{|c|c|c|c|c|c|c|c|}
\hline \multirow[b]{3}{*}{ Data collection week* } & \multicolumn{2}{|c|}{$\begin{array}{l}\text { Retrospective attendances } \\
\text { (2010/2011) }\end{array}$} & \multicolumn{5}{|c|}{ Prospective attendances (2012/2013) } \\
\hline & \multirow[b]{2}{*}{ All (n) } & \multirow{2}{*}{$\begin{array}{l}\text { Alcohol related } \\
\text { (n (\%)) }\end{array}$} & \multirow[b]{2}{*}{ All $(n)$} & \multirow{2}{*}{$\begin{array}{l}\text { Data availablet } \\
\text { (n (\%)) }\end{array}$} & \multicolumn{3}{|c|}{ Alcohol related $¥$} \\
\hline & & & & & All $(\mathrm{n}(\%))$ & $\operatorname{BrAC}(n(\%))$ & Clinical opinion (n (\%)) \\
\hline 2-8 July & 961 & $122(12.7)$ & 1622 & $656(40.4)$ & $101(15.4)$ & $90(13.7)$ & $11(1.7)$ \\
\hline 8-14 October & 1059 & $157(14.8)$ & 1691 & $1368(80.9)$ & $220(16.2)$ & $145(10.6)$ & $75(5.5)$ \\
\hline 17-23 December & 1464 & $171(11.7)$ & 1558 & $1298(83.3)$ & $186(14.3)$ & $100(7.7)$ & $86(6.6)$ \\
\hline \multirow[t]{2}{*}{25 February-3 March } & 1637 & $186(11.4)$ & 1655 & $1430(86.4)$ & $213(14.9)$ & $163(11.4)$ & $50(3.5)$ \\
\hline & 5121 & $636(12.4)$ & 6526 & $4752(72.8)$ & $720(15.2)$ & $498(10.5)$ & $222(4.7)$ \\
\hline \multicolumn{8}{|c|}{$\begin{array}{l}\text { NB percentages do not add to } 100 \text { due to rounding. } \\
\text { *Dates inclusive. } \\
\text { †As a percentage of total presentations. } \\
\text { ¥As a percentage of data available. } \\
\text { BrAC, breath alcohol concentration. }\end{array}$} \\
\hline
\end{tabular}


Due to the high proportion of negative cases from the BrAC test results from the prospective cohort, the scores were dichotomised into positive (any quantity of alcohol) and negative cases. The dichotomised scores were used as the dependent variable in a logistic regression to examine predictors of alcohol related attendances. The independent variables were gender, age group, week of attendance, day of the week, time of presentation and area. The week of attendance variable was dropped from the model because it was not significant. The HosmerLemeshow test was used to assess the goodness of fit.

The Paddington Alcohol Test was used to identify the 10 most common ED presentations associated with alcohol in both the retrospective and prospective datasets, ${ }^{20}$ although we added an extra code to identify patients with 'intoxication'.

A $\mathrm{z}$ test was used to test differences in proportions between the retrospective and prospective cohorts.

\section{RESULTS}

Across the 4 study weeks covered by retrospective data collection, 5121 adult patients presented to the ED, and during the prospective period 6526 adult patients presented (table 1). The overall prevalence rates of alcohol related attendances were $12.4 \%$ and $15.2 \%$ for the retrospective and prospective samples, respectively (table 2); this difference in proportions was significant $(Z=-3.9, p<0.001)$. For both cohorts, there were greater numbers of men than women in the alcohol related groups as well as a greater proportion of younger attendees. The temporal pattern of attendances for the alcohol related group for both datasets was similar, with higher proportions of alcohol related attendances on weekend days than weekdays and more attendances in night-time hours than daytime hours. Traumatic injury was the most common reason for attendance, followed by psychiatric problems for the alcohol related group.

The mean BrAC reading for all positive cases $(n=498)$ was $0.7 \mathrm{mg} / \mathrm{L}$ (SD 0.4). The results from the multiple logistic regression showed that the odds of having a positive BrAC test were significantly higher in men; for each age group compared with the 65 years and over age group; for patients attending on a weekend day compared with attending on a Monday; for patients attending in the evenings and early morning hours of the day compared with 6:00-11:59 in the morning; and for individuals who came from outside the region (ie, visitors to the city) compared with residents in northeast England (table 3). The Hosmer-Lemeshow test was not significant $(p=0.54)$ so the model is an adequate fit.

The data were further explored for interactions between the independent variables. A statistically significant interaction was found between age group and time of day (see online supplementary table S1). Figure 1 illustrates this interaction; alcohol related attendance in the early morning hours of the day was highest in the 18-24 year age group compared with the other age groups in the same time period.

Figure 2 illustrates the pattern of attendance for the prospective cohort; although the peak time of general attendance at the ED was 12:00 to 13:00, alcohol related attendances peaked between 2:00 and 3:00 at 59.0\%. Using the data for Fridays and Saturdays only, this percentage rose to a peak of $71.9 \%$ of attendances.

Exploring service use in the 12 months after attendance in the retrospective cohort, it was found that 102 of the 636 $(16.0 \%)$ attendances resulted in the patient being admitted to a ward or observation unit (table 4). Of those admitted, subsequent transfer to another ward was common $(n=29,28.4 \%$; data not shown), predominantly to the emergency assessment unit. The mean cost per attendance was $£ 249$ (SD $£ 1064$ ), with a best to worst scenario of $£ 173$ to $£ 316$. The majority of individuals however just incurred the cost of an attendance (£112), and hence the median cost and the associated IQR was $£ 112-$ $£ 112$. The mean cost for admissions (up to three admissions per patient) was $£ 851$ (SD $£ 2549$ ). As table 4 illustrates, the median costs are lower than mean costs, which indicates that a small number of individuals were very high users of services and this skewed the mean cost data to the right.

The costs broken down by gender and age showed that overall men used more NHS resources than women. Table 4 also shows that although older people may cost more per patient, younger people as a group are more costly to the NHS because they have more alcohol related attendances.

\section{DISCUSSION}

The overall prevalence rates of alcohol related attendances were $12 \%$ and $15 \%$ for the retrospective and prospective cohorts, respectively, with high variation according to the time of day and day of the week. On weekend days, over $70 \%$ of attendances were alcohol related, and these patients typically presented in the early hours of the morning. Alcohol related attendances were statistically more likely to be younger men visiting the ED in the early morning hours at weekends. The reason for attending the ED was similar across both samples, most commonly a traumatic injury, followed by psychiatric problems. The cost estimates to the NHS for alcohol related attendance at EDs ranged from $£ 173$ to $£ 316$, increasing substantially (mean $£ 851$ ) if hospital admission was required. Using conservative median costs, the emergency care in this hospital alone could be approximately $£ 1000000$ per annum for alcohol related attendances, although the true public sector cost could be much higher due to admissions and associated ambulance and police work. This indicates a significant NHS burden if all such EDs in the UK are sustaining similar demands associated with alcohol related attendance.

Patients with alcohol intoxication are often a complex group of patients to assess and treat. While some patients will simply sober up and leave, others present with a range of needs, from relatively minor injuries to high level care admission and further medical input. These patients can also present with challenging behaviour, brought on by intoxication, which can adversely impact on staff and other patients, who may experience delayed care. Thus it is important to identify the number and characteristics of alcohol related ED attendances to inform staffing decisions and potentially target preventive interventions. Our results suggest that EDs would benefit from routinely providing staff to cover the night and early morning shifts, particularly at weekends, to cope with the high proportion of alcohol related attendances at these times.

Previous retrospective studies reported prevalence rates ranging from $1 \%$ to $8 \% .^{10-12}$ However, our estimate was $12 \%$ using similar methods. Other prospective studies have reported prevalence rates ranging from 9\% to 40\%. ${ }^{13} 1518$ Although our prevalence rate of $15 \%$ is at the lower end of this range, this may be due to the fact that we included all times and days of the week rather than focusing on just the busiest weekend days. ${ }^{18}$ Our finding of a larger number of overall ED attendances in 2012/2013 compared with 2010/2011 reflects that this ED unit became over 20\% busier (partly due to an organisational change in the hospital) over the time frame of this study. Nevertheless, broadly similar prevalence rates and profiles of alcohol related attendances suggests a persistence in this 
Table 2 Descriptive information of samples and attendances

\begin{tabular}{|c|c|c|c|c|}
\hline & \multicolumn{2}{|l|}{ Retrospective* $(n=5121)$} & \multicolumn{2}{|l|}{ Prospectivet $(n=4752)$} \\
\hline & Not alcohol related $(\mathrm{n}(\%))$ & Alcohol ingested (n (\%)) & Not alcohol related $(\mathrm{n}(\%))$ & Alcohol related $(\mathrm{n}(\%))$ \\
\hline \multicolumn{5}{|l|}{ Sample } \\
\hline All & $4485(87.6)$ & $636(12.4)$ & $4032(84.8)$ & $720(15.2)$ \\
\hline \multicolumn{5}{|l|}{ Gender } \\
\hline Male & 2220 (83.5) & 439 (16.5) & $1847(81.0)$ & $432(19.0)$ \\
\hline Female & $2263(92.0)$ & $197(8.0)$ & $1854(89.8)$ & $210(10.2)$ \\
\hline Missing* & $2(0.0)$ & $0(0.0)$ & $331(8.2)$ & $78(10.8)$ \\
\hline \multicolumn{5}{|l|}{ Age (years) } \\
\hline $18-24$ & $961(80.6)$ & 231 (19.4) & $784(79.9)$ & 197 (20.1) \\
\hline $25-44$ & $1461(85.2)$ & $254(14.8)$ & $1022(83.8)$ & $197(16.2)$ \\
\hline $45-64$ & $976(89.5)$ & $114(10.5)$ & $760(88.6)$ & 98 (11.4) \\
\hline $65+$ & $1032(97.2)$ & $30(2.8)$ & $611(96.7)$ & $21(3.3)$ \\
\hline Missing* & $55(1.2)$ & $7(1.1)$ & $855(21.2)$ & $207(28.8)$ \\
\hline \multicolumn{5}{|l|}{ Area } \\
\hline NE postcode & $4125(88.9)$ & $517(11.1)$ & $2946(87.7)$ & $412(12.3)$ \\
\hline Other postcode & $345(74.8)$ & $116(25.2)$ & $177(73.4)$ & 64 (26.6) \\
\hline Missing* & $15(0.3)$ & $3(0.5)$ & $909(2.2)$ & $244(33.9)$ \\
\hline \multicolumn{5}{|l|}{ Attendances } \\
\hline \multicolumn{5}{|l|}{ Day of week } \\
\hline Monday & 717 (91.5) & $67(8.5)$ & $600(91.6)$ & $55(8.4)$ \\
\hline Tuesday & 605 (89.4) & 72 (10.6) & $548(89.7)$ & $63(10.3)$ \\
\hline Wednesday & $566(91.1)$ & $55(8.9)$ & $584(87.0)$ & $87(13.0)$ \\
\hline Thursday & $624(89.5)$ & $73(10.5)$ & $549(89.3)$ & $66(10.7)$ \\
\hline Friday & $648(87.2)$ & $95(12.8)$ & $475(83.0)$ & $97(17.0)$ \\
\hline Saturday & $646(82.6)$ & $136(17.4)$ & $603(76.1)$ & $189(23.9)$ \\
\hline Sunday & $679(83.1)$ & $138(16.9)$ & $665(80.3)$ & $163(19.7)$ \\
\hline Missing* & - & - & $8(0.2)$ & $0(0.0)$ \\
\hline \multicolumn{5}{|l|}{ Time of day } \\
\hline Midnight-5:59 & $526(64.5)$ & $289(35.5)$ & $390(52.3)$ & $356(47.7)$ \\
\hline 6:00-11:59 & $1167(95.0)$ & $63(5.1)$ & 1062 (94.3) & $64(5.7)$ \\
\hline Noon-17:59 & $1612(94.2)$ & $100(5.9)$ & $1529(94.9)$ & $82(5.1)$ \\
\hline $18: 00-23: 59$ & $1180(86.5)$ & $184(13.5)$ & $964(82.8)$ & $200(17.2)$ \\
\hline Missing* & - & - & $87(1.8)$ & $18(0.4)$ \\
\hline \multicolumn{5}{|l|}{ Week of year } \\
\hline 2-8 July & $839(87.3)$ & $122(12.7)$ & $555(84.6)$ & $101(15.4)$ \\
\hline 8-14 October & $902(85.2)$ & $157(14.8)$ & $1148(83.9)$ & $220(16.1)$ \\
\hline 17-23 December & $1293(88.3)$ & $171(11.7)$ & 1112 (85.7) & $186(14.3)$ \\
\hline 25 February-3 March & $1451(88.6)$ & $186(11.4)$ & $1217(85.1)$ & $213(14.9)$ \\
\hline \multicolumn{5}{|l|}{ Reason for attendance $\ddagger$} \\
\hline Fall & $50(84.8)$ & $9(15.3)$ & $148(82.7)$ & $31(17.3)$ \\
\hline Collapse (including fits) & $199(82.2)$ & $43(17.8)$ & $128(88.9)$ & $16(11.1)$ \\
\hline Head injury & 119 (68.9) & 55 (31.6) & $67(62.6)$ & $40(37.4)$ \\
\hline Assault & $29(46.0)$ & $34(54.0)$ & $22(31.4)$ & $48(68.6)$ \\
\hline Accident & $1025(90.1)$ & $113(9.9)$ & $956(87.7)$ & $134(12.3)$ \\
\hline Unwell & $143(94.1)$ & $9(5.9)$ & $44(97.8)$ & $1(2.2)$ \\
\hline Gastrointestinal & 351 (93.9) & $23(6.2)$ & $272(91.3)$ & $26(8.7)$ \\
\hline Psychiatric & 89 (58.6) & $63(41.5)$ & $63(50.8)$ & $61(49.2)$ \\
\hline Cardiac (including chest pain) & $320(96.7)$ & $11(3.3)$ & 257 (96.6) & $9(3.4)$ \\
\hline Repeat attender§ & Unknown & Not included & Unknown & Unknown \\
\hline Intoxicationๆ & $6(4.0)$ & $144(96.0)$ & $4(4.4)$ & 88 (95.6) \\
\hline Other & 1662 (97.6) & $41(2.4)$ & 1161 (95.5) & $55(4.5)$ \\
\hline Missing* & $492(9.6)$ & $91(1.8)$ & $910(19.1)$ & $211(4.4)$ \\
\hline
\end{tabular}


Table 3 Multiple logistic regression of positive breath alcohol concentration test on gender, age, day of the week, time of presentation and postcode (prospective dataset)

\begin{tabular}{|c|c|c|c|c|c|}
\hline & OR & SE & $z$ & $P>z$ & $95 \% \mathrm{Cl}$ \\
\hline \multicolumn{6}{|l|}{ Gender } \\
\hline Male & 1.00 & & & & \\
\hline Female & 0.58 & 0.07 & -4.59 & $<0.01$ & 0.46 to 0.73 \\
\hline \multicolumn{6}{|l|}{ Age group (years) } \\
\hline 65 and over & 1.00 & & & & \\
\hline $45-64$ & 4.03 & 1.11 & 5.08 & $<0.01$ & 2.35 to 6.90 \\
\hline $25-44$ & 5.31 & 1.39 & 6.38 & $<0.01$ & 3.18 to 8.87 \\
\hline $18-24$ & 5.78 & 1.52 & 6.68 & $<0.01$ & 3.45 to 9.66 \\
\hline \multicolumn{6}{|l|}{ Day of week } \\
\hline Monday & 1.00 & & & & \\
\hline Tuesday & 1.53 & 0.39 & 1.69 & 0.09 & 0.93 to 2.52 \\
\hline Wednesday & 1.64 & 0.41 & 2.00 & 0.05 & 1.01 to 2.66 \\
\hline Thursday & 1.50 & 0.38 & 1.60 & 0.11 & 0.91 to 2.48 \\
\hline Friday & 2.49 & 0.63 & 3.61 & $<0.01$ & 1.52 to 4.10 \\
\hline Saturday & 3.74 & 0.88 & 5.59 & $<0.01$ & 2.35 to 5.94 \\
\hline Sunday & 3.27 & 0.76 & 5.10 & $<0.01$ & 2.07 to 5.15 \\
\hline \multicolumn{6}{|l|}{ Time of day } \\
\hline 06:00-11:59 & 1.00 & & & & \\
\hline Noon-17:59 & 0.82 & 0.18 & -0.91 & 0.36 & 0.54 to 1.25 \\
\hline $18: 00-23: 59$ & 3.86 & 0.72 & 7.26 & $<0.01$ & 2.68 to 5.56 \\
\hline Midnight-05:59 & 17.04 & 3.19 & 15.17 & $<0.01$ & 11.81 to 24.59 \\
\hline \multicolumn{6}{|l|}{ Area } \\
\hline NE postcode & 1.00 & & & & \\
\hline Other & 1.92 & 0.38 & 3.27 & $<0.01$ & 1.30 to 2.83 \\
\hline
\end{tabular}

significantly sized but avoidable area of work. While our mean cost of a primary visit of $£ 249$ was lower than that recently reported in Belgium of $£ 400,{ }^{10}$ when follow-up treatment costs are allowed for, the true average cost per patient rises substantially. Previous international studies have reported that alcohol related attendances are strongly associated with mental health disorders ${ }^{10} 11{ }^{13}$; which our work confirms in a UK setting. This emphasises the importance of liaison psychiatry services to address the mental health needs of patients being treated for physical conditions. $^{21}$

By using a combination of measures across entire weeks and all seasons, we overcame the problem of measuring maximum

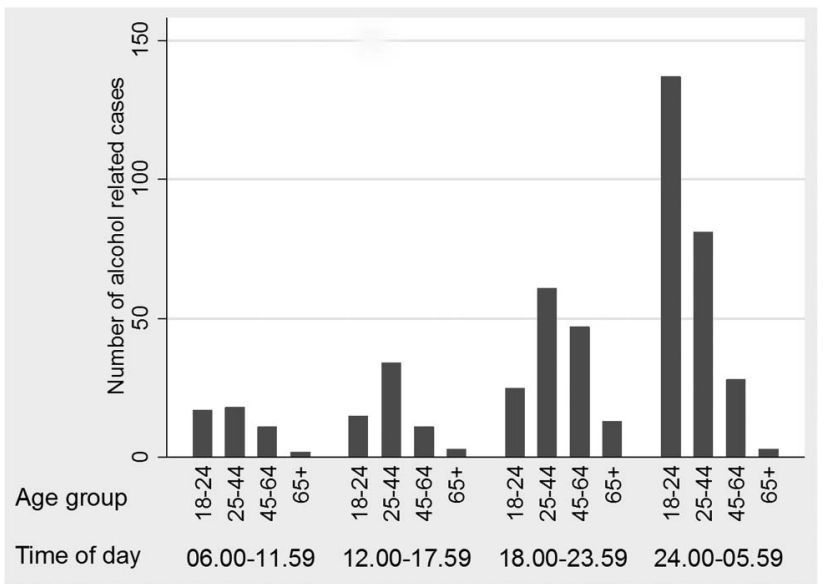

Figure 1 Breath alcohol concentration positive patients by age group and time of day.
A by hour of attendance for entire weeks

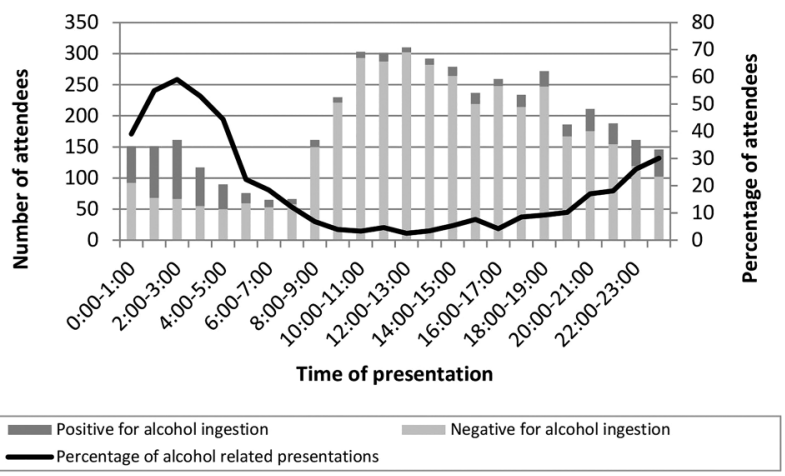

B by hour of attendance for midnight Friday to midnight Sunday

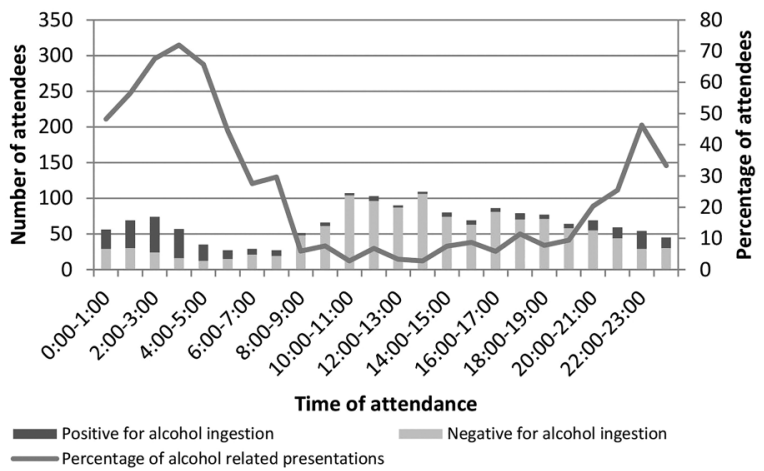

$\mathrm{BrAC}$, breath alcohol concentration

Figure 2 Breath alcohol concentration positive and negative patients by hour of attendance for entire weeks $(A)$ and by hour of attendance for midnight Friday to midnight Sunday (B).

attendance only (eg, at weekends or at a particular time of year when events such as festive holiday may bias results). This study confirms the evidence from previous work reporting a high prevalence of alcohol related attendances at weekends and in the early hours of the morning. ${ }^{18}$ Even using a simple dichotomised measure of negative and positive BrAC scores we were able to show that alcohol related attendances are more highly associated with being male, being younger, attending at weekends and in the early morning hours. Our observation that individuals who travelled into the city had significantly higher odds of a positive breath alcohol test than local residents confirms the idea that city centres attract revellers from elsewhere. However, the cost burden often falls on city hospitals and other local public sector services. $^{22}$

We encountered initial difficulty in implementing our first week of prospective data collection due to staff breaks and staff handover times; strategies were put in place to address this by ensuring more staff were available at critical times. The subsequent weeks achieved a high response rate (over 80\% each week) and therefore we believe our data provide an accurate and generalisable dataset. Nevertheless, it is worth speculating on the effect the missing data may have had on the results; anecdotally, it was reported that sober patients were generally amenable to providing a breath sample while waiting for treatment, and that declining to participate and absconding, for example, tended to be by intoxicated patients. We therefore propose that any effect is more likely to have led to our prevalence rates of alcohol related attendance being underestimates rather than overestimates. 
Table 4 Costs to National Health Service of alcohol related emergency department attendance (f) (retrospective dataset)

\begin{tabular}{|c|c|c|c|c|c|}
\hline & \multirow[b]{2}{*}{$\mathrm{N}$} & \multicolumn{2}{|l|}{ Cost } & \multirow{2}{*}{$\begin{array}{l}\text { Best case scenario* } \\
\text { Mean (SD) }\end{array}$} & \multirow{2}{*}{$\begin{array}{l}\text { Worst case scenario* } \\
\text { Mean (SD) }\end{array}$} \\
\hline & & Mean (SD) & Median (IQR range) & & \\
\hline \multicolumn{6}{|l|}{ Attendances and admissions } \\
\hline Overall cost of attendancet & 636 & 249 (1064) & $112(112-112)$ & 173 (933) & 316 (1232) \\
\hline Cost of first ward & 102 & $338(620)$ & $46(1-342)$ & $297(529)$ & $423(702)$ \\
\hline Cost of second ward & 29 & $1438(4558)$ & $293(134-1166)$ & $1229(4032)$ & 1693 (5249) \\
\hline Cost of third ward & 13 & 818 (730) & $601(236-1138)$ & 722 (645) & 944 (842) \\
\hline Total ward admission costł & 102 & 851 (2549) & $294(5-916)$ & 738 (2238) & 1024 (2934) \\
\hline \multicolumn{6}{|l|}{ Costs by gender and age } \\
\hline \multicolumn{6}{|l|}{ Male (years) } \\
\hline $18-24$ & 153 & $166(368)$ & $112(112-112)$ & & \\
\hline $25-44$ & 169 & $269(481)$ & $112(112-112)$ & & \\
\hline $45-64$ & 84 & $171(292)$ & $112(112-112)$ & & \\
\hline $65+\S$ & 27 & 1324 (4809) & $112(112-112)$ & & \\
\hline \multicolumn{6}{|l|}{ Female (years) } \\
\hline $18-24$ & 78 & $126(68)$ & $112(112-112)$ & & \\
\hline $25-44$ & 85 & 199 (324) & 112 (112-112) & & \\
\hline $45-64$ & 30 & 305 (498) & $112(112-112)$ & & \\
\hline $65+$ & 3 & $302(328)$ & $112(112-112)$ & & \\
\hline
\end{tabular}

We acknowledge the limitation of using a single site. However, we found a similar peak in alcohol related attendances of approximately $70 \%$ in the early hours of the morning as a larger national study in the UK which was based on data from a $24 \mathrm{~h}$ period (Saturday night to Sunday morning) in the month of June. ${ }^{18}$ What our work adds is a wider view over all days of the week and all seasons of the year.

Having established a clear estimate of the prevalence of alcohol related attendances in ED, the next critical step is to implement strategies to reduce this potentially avoidable work. There is good evidence that referral for brief intervention results in reduced re-attendance for ED. ${ }^{5}$ There is also evidence supporting the idea of training paramedics to work with patients with alcohol related injury or illness at the scene of the first contact which could directly benefit the patient and the ambulance service by reducing frequent and regular callers known to have alcohol problems. ${ }^{23}$ In England there have been improvements in the recognition of alcohol misuse in EDs following recommendations from the Department of Health that brief advice should be provided in health settings such as EDs. ${ }^{24}$ From our study, we can recommend that a pragmatic approach for EDs to cope with the influx of alcohol related attendances will be to routinely provide staff to cover the night and early morning shifts, particularly at weekends, to enable brief intervention delivery that can help to reduce subsequent alcohol consumption and its related problems. ${ }^{25}$

Acknowledgements We are grateful to Newcastle Healthcare Charity for funding the breath testing equipment. We thank the emergency department team at the Royal Victoria Infirmary, Newcastle upon Tyne, for supporting the study, and the administration staff. We thank the research nurses and other emergency department staff for their work to make the project a success.

Contributors KP contributed to the coordination of the study, data handling and was responsible for writing the manuscript. EK, JC, JW, LV, DN-B and PH were responsible for the study design. EK was responsible for the overall execution of the study and JC for the clinical management of the study. LV designed and supervised the health economics analysis. ES conducted all statistical analyses. AP was responsible for retrospective data handling. All co-authors contributed to writing the manuscript.

Funding The study grant was awarded by the Newcastle upon Tyne Hospitals NHS Foundation Trust: Flexibility and Sustainability Funding, reference FSF1112.

Competing interests None declared.

Ethics approval The study was approved by the NRES Committee North East-Newcastle and North Tyneside 2 REC Reference 12/NE/0063.

Provenance and peer review Not commissioned; externally peer reviewed.

Open Access This is an Open Access article distributed in accordance with the Creative Commons Attribution Non Commercial (CC BY-NC 4.0) license, which permits others to distribute, remix, adapt, build upon this work non-commercially, and license their derivative works on different terms, provided the original work is properly cited and the use is non-commercial. See: http://creativecommons.org/ licenses/by-nc/4.0/

\section{REFERENCES}

1 Lim SS, Vos T, Flaxman AD, et al. A comparative risk assessment of burden of disease and injury attributable to 67 risk factors and risk factor clusters in 21 regions, 1990-2010: a systematic analysis for the Global Burden of Disease Study 2010. Lancet 2012;380:2224-60

2 Baumberg B. The global economic burden of alcohol: a review and some suggestions. Drug Alcohol Rev 2006;25:537-51.

3 Rehm J, Mathers C, Popova S, et al. Global burden of disease and injury and economic cost attributable to alcohol use and alcohol-use disorders. Lancet 2009;373:2223-33.

4 Barrett B, Byford S, Crawford MJ, et al. Cost-effectiveness of screening and referral to an alcohol health worker in alcohol misusing patients attending an accident and emergency department: a decision-making approach. Drug Alcohol Depend 2006;81:47-54

5 Crawford MJ, Patton R, Touquet R, et al. Screening and referral for brief intervention of alcohol-misusing patients in an emergency department: a pragmatic randomised controlled trial. Lancet 2004;364:1334-9.

6 Longabaugh R, Woolard RF, Nirenberg TD, et al. Evaluating the effects of a brief motivational intervention for injured drinkers in the emergency department. J Stud Alcohol 2001;62:806-16.

7 Monti PM, Colby SM, Barnett NP, et al. Brief intervention for harm reduction with alcohol-positive older adolescents in a hospital emergency department. J Consult Clin Psychol 1999;67:989-94.

8 MacLeod JBA, Hungerford DW. Alcohol-related injury visits: Do we know the true prevalence in U.S. trauma centres? Injury 2011;42:922-6. 
9 Kowalenko T, Burgess B, Szpunar SM, et al. Alcohol and trauma in every age group. Am J Emerg Med 2013;31:705-9.

10 Verelst S, Moonen P-J, Desruelles D, et al. Emergency department visits due to alcohol intoxication: characteristics of patients and impact on the emergency room. Alcohol Alcohol 2012;47:433-8.

11 Indig D, Copeland J, Conigrave KM, et al. Characteristics and comorbidity of drug and alcohol-related emergency department presentations detected by nursing triage text. Addiction 2010;105:897-906.

12 Newton A, Sarker SJ, Pahal GS, et al. Impact of the new UK licensing law on emergency hospital attendances: a cohort study. Emerg Med J 2007;24:532-4.

13 Havard A, Shakeshaft AP, Conigrave KM, et al. The prevalence and characteristics of alcohol-related presentations to emergency departments in rural Australia. Emerg Med J 2011;28:290-5.

14 Tjipto AC, Taylor DM, Liew H. Alcohol use among young adults presenting to the emergency department. Emerg Med Australas 2006;18: 125-30

15 Hoskins R, Benger J. What is the burden of alcohol-related injuries in an inner city emergency department? Emerg Med J 2013;30:e21.

16 Espitia-Hardeman V, Hungerford D, Hill HA, et al. Alcohol-associated injury visits to emergency departments in Pasto, Colombia in 2006. Int I Inj Contr Saf Promot 2010;17:129-33.

17 Plüddemann A, Parry C, Donson $\mathrm{H}$, et al. Alcohol use and trauma in Cape Town, Durban and Port Elizabeth, South Africa: 1999-2001. Inj Control Saf Promot 2004:11:265-7.
18 Drummond C, Phillips T, Coulton S, et al. Saturday night and Sunday morning: The 2003 twenty-four hour national prevalence survey of alcohol-related attendances at accident and emergency departments in England. Final Report to the Cabinet Office, 2003.

19 Curtis L. Unit costs of health and social care. Personal Social Services Research Unit, University of Kent, 2013.

20 Smith SG, Touquet R, Wright $S$, et al. Detection of alcohol misusing patients in accident and emergency departments: the Paddington alcohol test (PAT). J Accid Emerg Med 1996;13:308-12.

21 Tadros G, Salama RA, Kingston P, et al. Impact of an integrated rapid response psychiatric liaison team on quality improvement and cost savings: the Birmingham RAID model. Psychiatrist 2013;37:4-10.

22 Martin N, Newbury-Birch D, Duckett J, et al. A retrospective analysis of the nature, extent and cost of alcohol-related emergency calls to the ambulance service in an English region. Alcohol Alcohol 2012;47:197-7.

23 Glencorse M, Wilson G, Newbury-Birch D. Paramedic perceptions and attitudes to working with patiens with alcohol-related injury or illness. J Paramedic Pract 2014;6:310-18

24 Patton R, O'Hara P. Alcohol: signs of improvement. The 2nd national emergency department survey of alcohol identification and intervention activity. Emerg Med J 2013;30:492-5

25 Drummond C, Deluca P, Coulton S, et al. The effectiveness of alcohol screening and brief intervention in emergency departments: a multicentre pragmatic cluster randomized controlled trial. PLOS ONE 2014;9:e99463. 